\title{
Analisa Dan Perancangan Sistem Informasi Kepegawaian Di UPTD BSPM Provinsi Banten
}

\author{
Fanny Fransisca \\ Program Studi Teknik Informatika \\ STMIK Buddhi \\ Jl. Imam Bonjol No. 41 Karawaci Ilir, Tangerang 15115 \\ stelovfan@gmail.com
}

\begin{abstract}
As the development of information technology, the more influence on a variety of organizations and agencies, especially the world of work environment in which there were kinds of data processing, that was difficult if only done by a manual system or the systems that were classified into non effective system. Nowadays, UPTD BSPM Banten province has been applied for non effective system. Despite of its data processing already used computer but the application was microsoft office. As the solution of these problems required an effective system that was Human Resources Information System that will provide better performance in data processing at UPTD BSPM Banten Province. By the existence of the system, it will provide even more comfort in the process of data processing and it also provides information services fast, precise and accurate.
\end{abstract}

Kata Kunci- UPTD BSPM Banten, Human Resources Information System, Information

\section{Pendahuluan}

Bersamaan dengan perkembangan tingkat Teknologi informasi yang semakin tahun semakin tinggi dan pesat pada saat ini telah memicu berbagai macam metode baru untuk pengolahan data dan informasi yang berhubungan dengan semua sistem yang ada pada prusahaan, instansi dan organisasi. Oleh karena itu diperlukan untuk setiap perusahaan, instansi, dan organisasi termasuk UPTD BSPM Provinsi Banten menerapkan sistem yang terkomputerisasi untuk pengolahan data pegawai sehinga akan memudahkan segala proses pengolahan data pegawai mulai dari penginputan sampai penyimpanan dan menambah tingkat keakuratan keamanan dan keefisienan sistem pada pegolahan data pegawai. Dari hasil survey yang telah dilakukan pada UPTD BSPM Provinsi Banten proses pengolahan data pegawai yang ada masih kurang efektif yaitu penginputan dan penyimpanan datanya hanya dengan menggunakan sistem operasi yang ada di komputer saja maka data pegawai yang tersimpan pun masih sering hilang dan tidak akurat juga data yang tersimpan tidak beraturan dan masih sering terjadi kesalahan dalam penginputannya dan karena itu juga keamanan data pegawai pun masih sangan minim. Berdasarkan permasalahan tersebut, maka dirancnag sebuha sistem informasi kepegawaian yang bertujuan untuk mempermudah pengolahan data pegawai yang lebih akurat, aman,mudah dan efisien bagi para pegawai di instansi.

\section{LANDASAN TEORI}

\section{A. Konsep Sistem}

Sistem merupakan komponen-komponen atau sub sistem yang saling berinteraksi satu sama lain, dimana masingmasing bagian tersebut dapat bekerja secara sendiri-sendiri (independent) atau bersama-sama serta saling berhubungan membentuk satu keatuan sehingga tujuan atau sasaran sistem tersebut dapat tercapai secara keseluruhan [1].

\section{B. Manajemen Proyek}

Manajemen adalah aplikasi dari pengetahuan, keahlian, tools teknologi untuk aktivitas proyek dalam upaya mempertemukan atau melebihi kebutuhan dan harapan stakeholder terhadap proyek[1]. Manajemen proyek menurut PMBOK adalah aplikasi dari pengetahuan, keahlian tools, teknologi untuk aktivitas proyek dengan tujuan memenuhi permintaan proyek. Manajemen proyek terpenuhi melalui proses, menggunakan pengetahuan manajemen proyek, keahlian, tools, dan teknik yang menerima input dan menghasilkan output..

\section{Visual Basic 2008 (VB.Net)}

Visual basic adalah bahasa pemrograman Basic merupakan bahasa pemrograman Basic. Bahasa pemrograman Basic merupakan bahasa pemrograman yang sangat populer dikembangkan dari tahun 1963. Visual basic merupakan bahasa yang dikembangkan dari basic yang ditujukan untuk membuat program cepat dengan tampilan GUI (Graphical User Interface ). Bahasa pemograman Visual Basic merupakan bahasa pemograman utama dari perusahaan Microsof Inc yang 
paling sukses hingga duabelas tahun.Bahasa pemograman ini menjadi contoh semua bahasa pemograman RAD. Hingga tahun ini kepopuleran bahasa pemograman Visual Basic 6.0 masih bertahan kuat karena kemudahan, ringan, dan handal[2].

\section{Metode Penelitian}

\section{A. Project Execution Plan (PEP)}

Proses mengkoordinasikan seumber daya yang ada untuk menjalankan sejumlah pekerjaan didalam proyek agar menghasilkan produk yang sesuai dengan yang telah ditargetkan Responbsibility Assigment Matrik (RAM).

\section{B. Penjadwalan Proyek}

Penjadwalan proyek adalah kegiatan menetapkan jangka waktu kegiatan proyek yang harus diselesaikan, bahan baku, tenaga kerja serta waktu yang dibutuhkan oleh setiap aktivitas dan harus secara terorganisasi utnuk menciptakan suatu output (keluaran) yang tersetruktur bagi manajemen dalam penentuan progress atau tujuan.

\section{Responsible Assigmnet Matrik (RAM)}

Memetakan pekerjaan proyek, seperti yang dijelaskan dalam work breakdown structure, kepada orang-orang yang bertanggung jawab untuk melaksanakan pekerjaan serta dapat dibuat dengan cara yang berbeda dengan mengguanakan metode RACI untuk memnuhi kebutuhan proyek.

\section{Hasil dan Pembahasan}

\section{A. Use Case Diagram}

1) Use Case Diagram Package

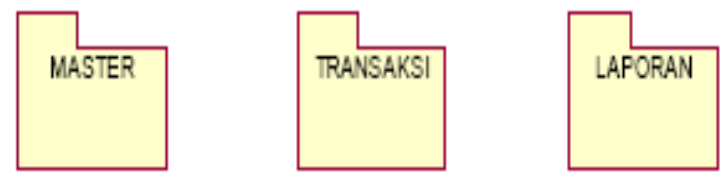

Gambar 1. Use Case Diagram Package

2) Use Case Diagram Master

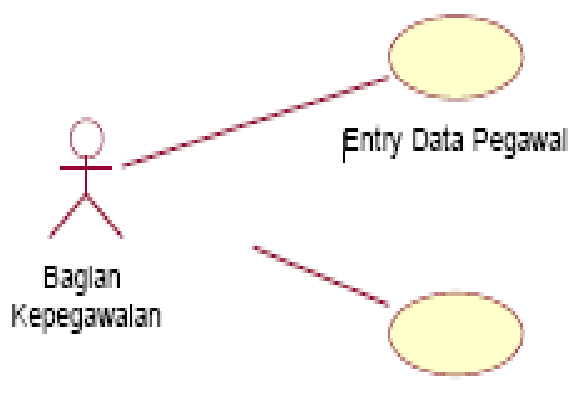

Entry Data Absens|

Gambar 2. Use Case Diagram Master
3) Usecase Diagram Transaksi

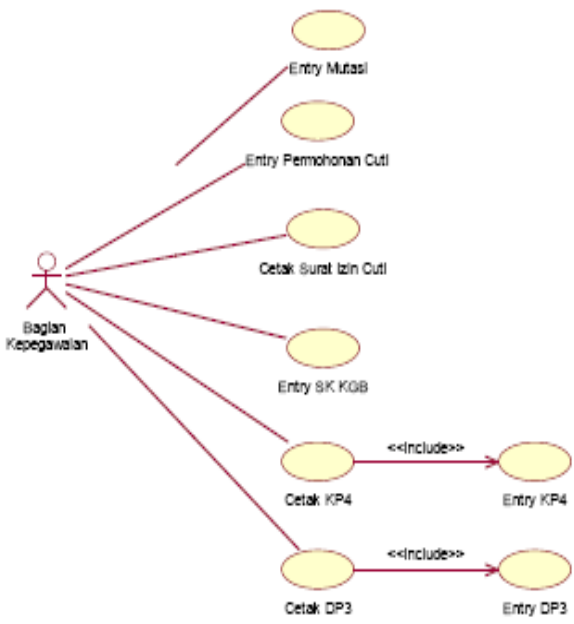

Gambar 2. Use Case Diagram Transaksi

4) Use Case Diagram Laporan

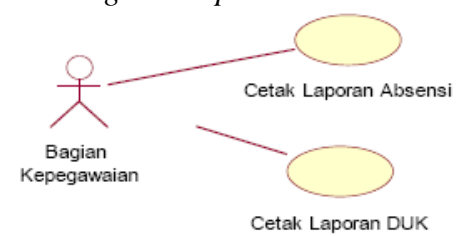

Gambar 4. Use Case Diagram Laporan

B. Entity Relationship Diagram (ERD)

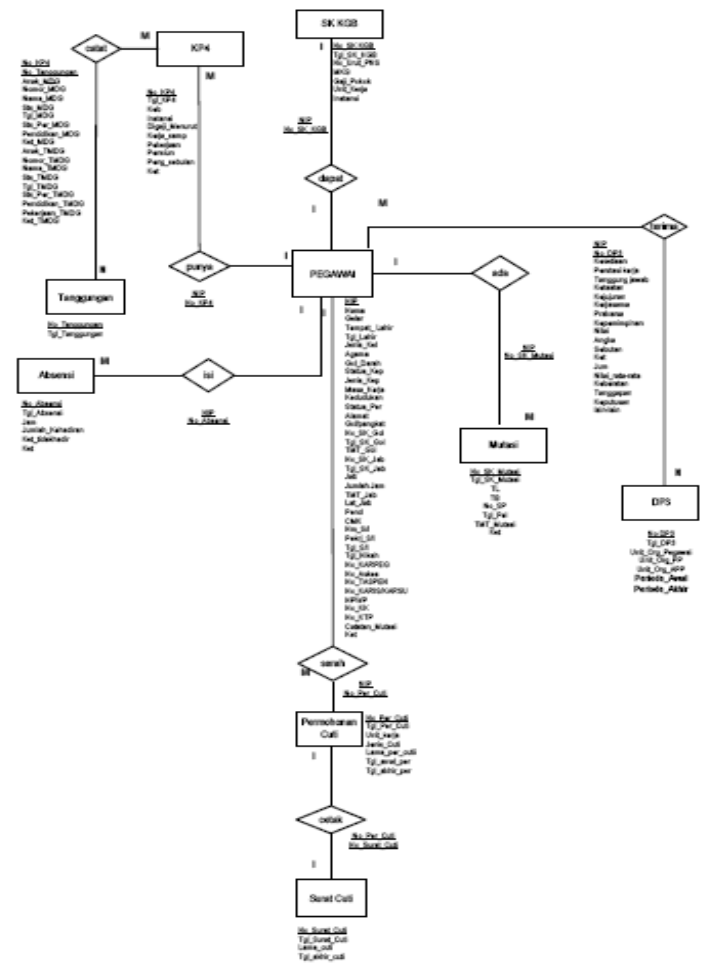

Gambar 5. Entity Relationship Diagram 
C. Struktur Tampilan

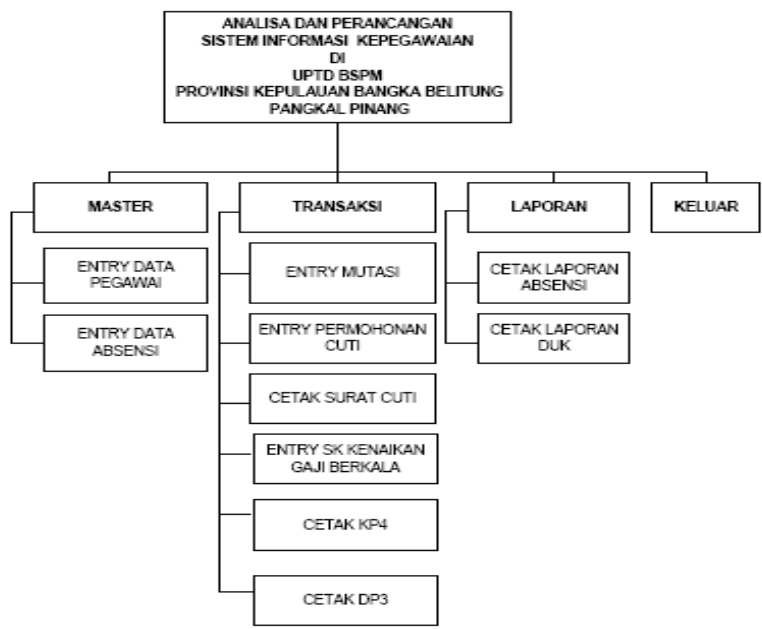

Gambar 6. Struktur Tampilan

D. Rancangan Layar

1) Rancangan Layar Menu Utama

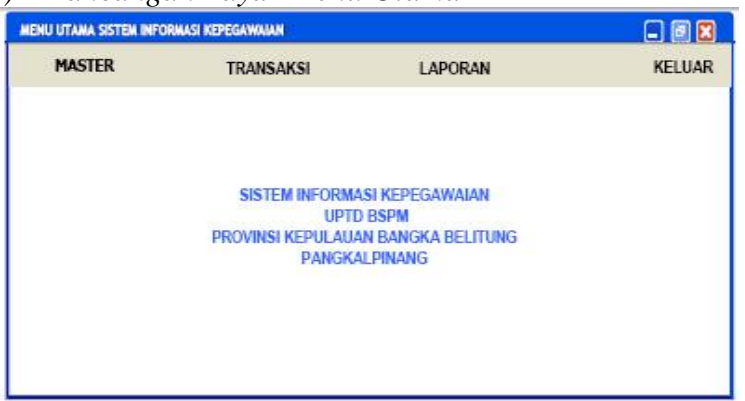

Gambar 7. Rancangan Layar Menu Utama

2) Tampilan Layar Entry Data Pegawai

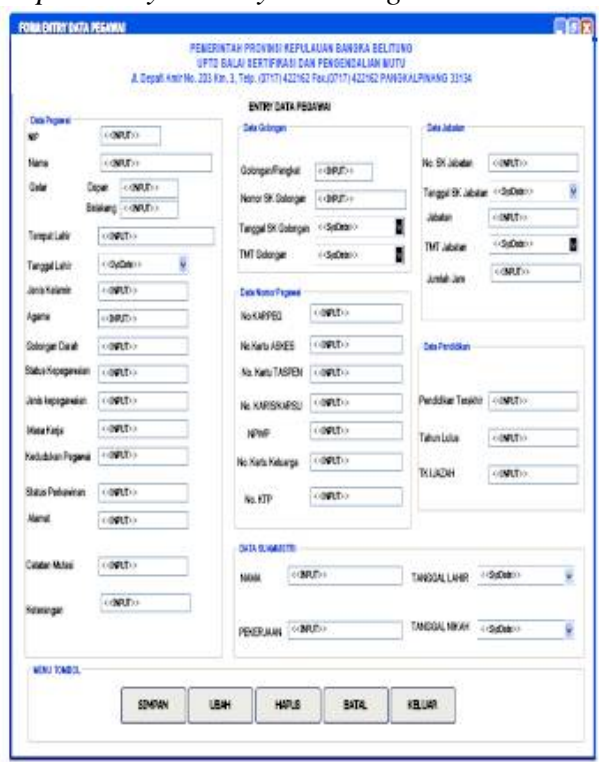

Gambar 8. Rancangan Layar Entri Data Pegawai
3) Rancangan Layar Entry Data Permohonan Cuti

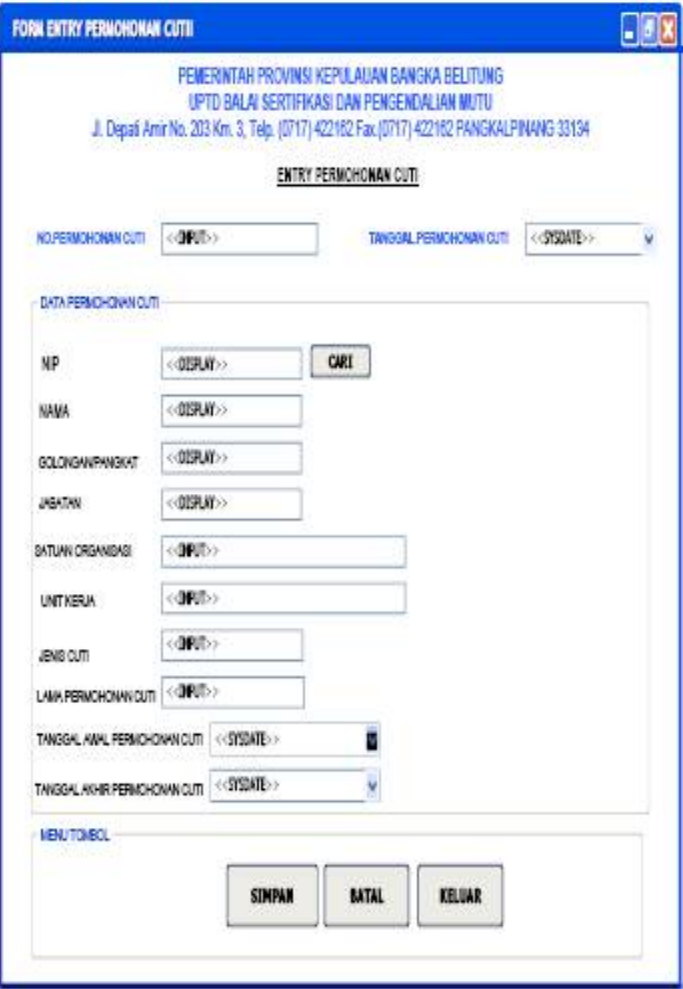

Gambar 10. Rancangan Layar Entry Data permohonan Cuti

4) Rancangan Layar Cetak Surat Cuti

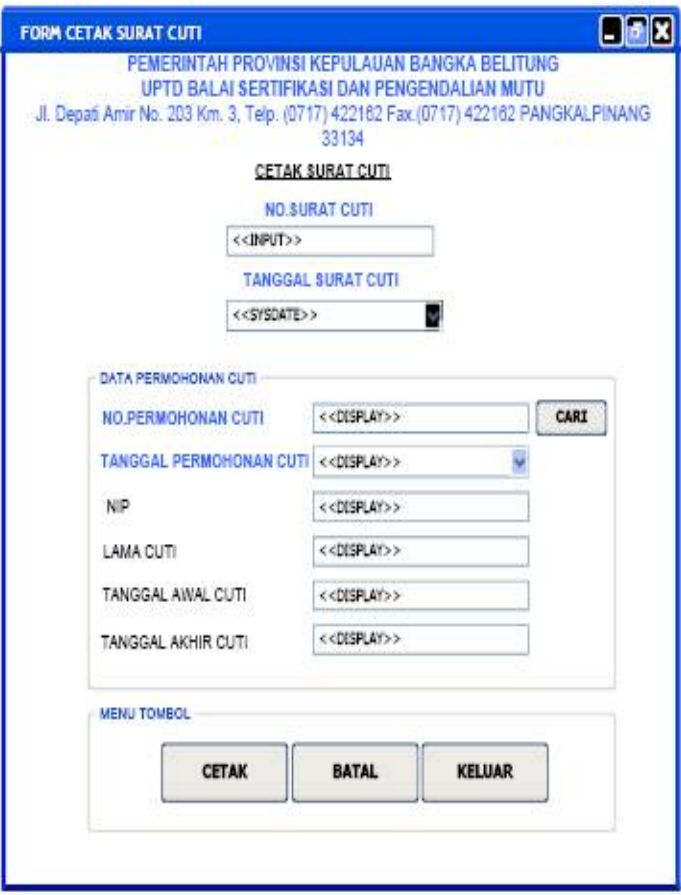

Gambar 6. Rancangan Layar Cetak Surat Cuti 


\section{E. Sequence Diagram}

1) Sequence Diagram Entri Data Pegawai

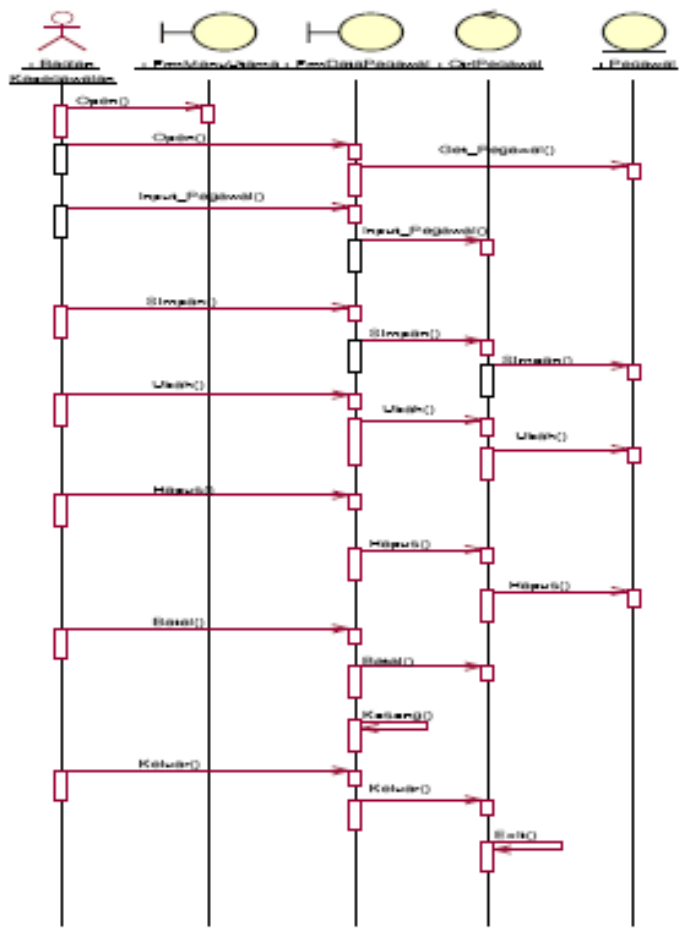

Gambar 11. Sequence diagram Entri Data Pegawai 2) Sequence Diagram Entry Permohonan Cuti

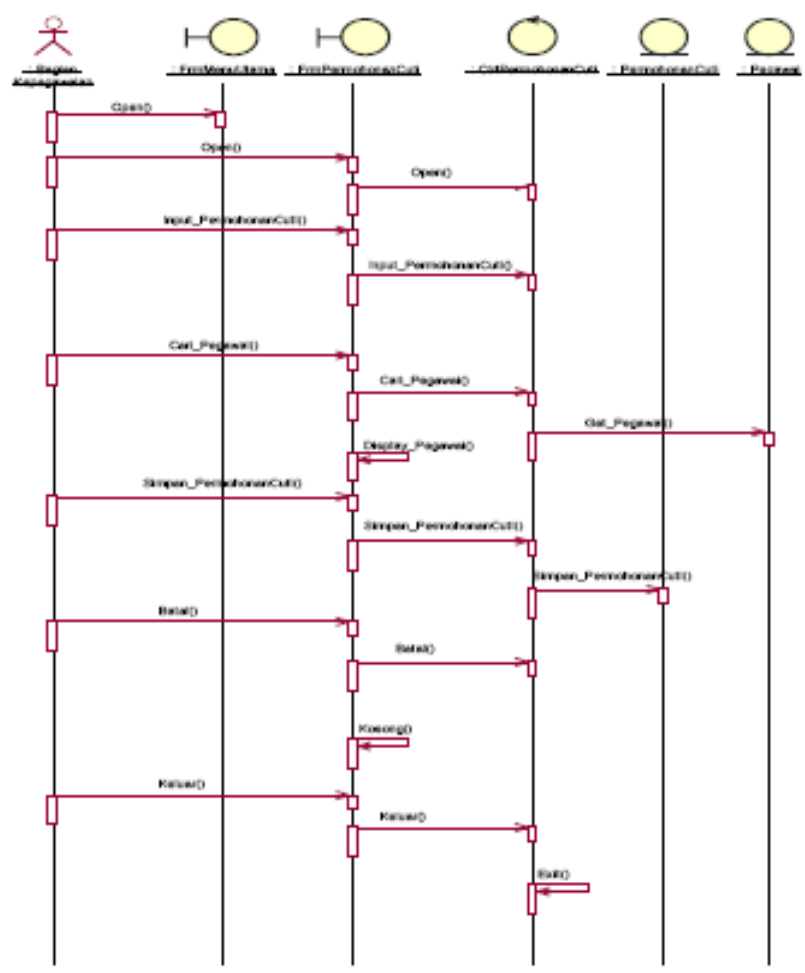

Gambar 12. Sequence diagram Entri permohonan Cuti

\section{3) Sequence Diagram Cetak Surat Cuti}

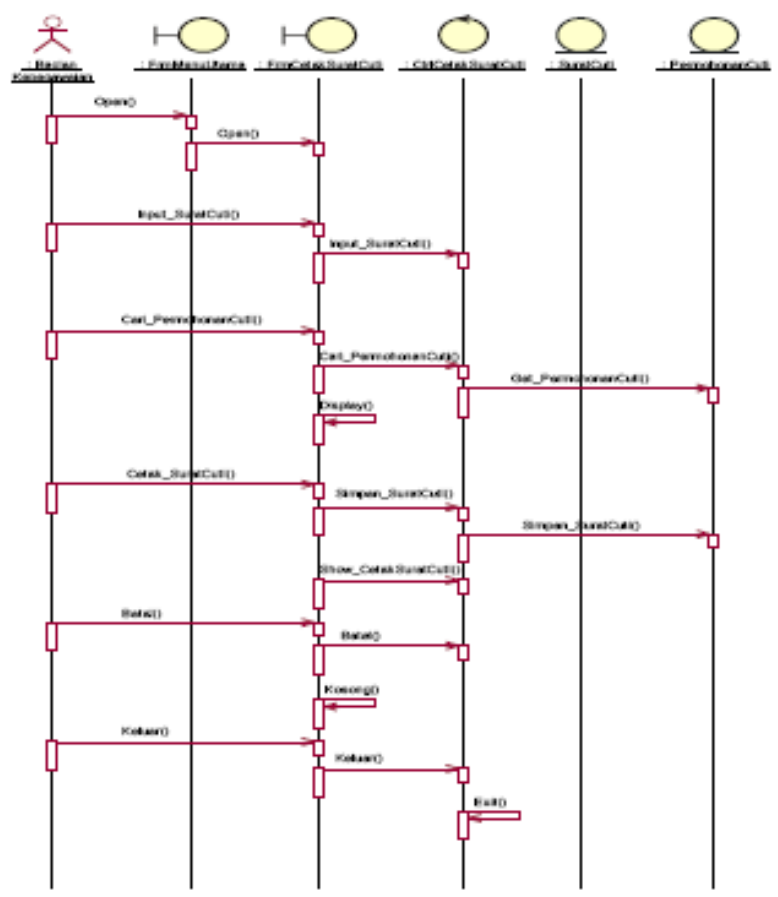

Gambar 13. Sequence Diagram Cetak Surat Cuti

\section{Penutup}

\section{A. Kesimpulan}

Beberapa kesimpulan yang bisa diambil dengan telah diselesaikannya laporan Skripsi Analisa dan Perancangan Sistem Informasi Kepegawaian telah dapat menangani masalah bagi Instansi Dinas UPTD BSPM Kepulauan Banten sebagai berikut :

- Sistem kepegawaian yang ada selama ini masih menggunakan cara manual sehingga memperlambat penerimaan informasi pada proses kepegawian dan dengan sistem yang baru maka informasi kepegawaian pada UPTD BSPM Provinsi Kepualuan Banten bisa lebih maksimal.

- Pengolahan data, pencarian data dan pembuatan laporan sudah dilakukan secara terkomputerisasi sehingga informasi yang dihasilkan menjadi lebih baik.

- Rancangan aplikasi sistem informasi kepegawian ini dapat digunakan untuk membantu pegawai dalam melakukan pengolahan data dan meminimalkan tingkat kesalahan yang biasanya terjadi dalam sistem manual.

- Penggunaan sistem informasi yang baru ini tidak akan merusak sistem yang selama ini berjalan di UPTD BSPM, tetapi dengan sistem ini diharapkan dapat lebih mendukung kinerja proses pengolahan data pada sistem kepegawaian sehingga lebih efisien.

- Kelebihan dari sistem ini jika diterapkan oleh UPTD BSPM Provinsi Kepulauan Banten yaitu bisa lebih menghemat waktu untuk pencarian data dan 
penginputan data. serta dapat menyajikan informasi secara cepat, tepat dan akurat.

\section{B. Saran}

Dengan kesimpulan diatas, maka penulis dapat sedikit memberikan saran-saran antara lain sebagai berikut:

- Memaksimalkan pekerjaan, maka sistem pengolahan data kepegawaian yang masih dilakukan secara manual perlu untuk diganti dengan menerapkan sistem yang lebih baik yaitu sistem informasi yang terkomputerisasi.

- Sistem Informasi Kepegawaian yang penulis bangun semoga dapat diterapkan dan dapat membantu UPTD BSPM Provinsi Kepulauan Banten dan bagian kepegawaian hendaknya mempelajari terlebih dulu aplikasi ini agar bisa lebih memahami dan memudahkan bagian kepagawaian

\section{DAFTAR PUSTAKA}

[1] Helda Purwati, 2013. Analisa dan Perancangan Sistem Informasi Administrasi Kepegawaian Pangkalpinang.

[2] Ir.Yuniar Supardi, Semua bisa menjadi programer VB6 hingga VB 2008. Yogyakarta:PT Elexmedia, 2013.

[3] Munawar, (2005), Pemodelan Visual dengan UML, Graha Ilmu, Yogyakarta.

[4] M. Faisal, (2011), flowchart diagram alur, Mandar, diakses pada 2 Juni 2014, <http://www.mandar.web.id/>. 